\title{
Development and testing of a self administered version of the Freezing of Gait Questionnaire
}

\author{
Maria H Nilsson ${ }^{1,2^{*}}$, Gun-Marie Hariz ${ }^{3,4}$, Klas Wictorin ${ }^{5}$, Michael Miller ${ }^{1}$, Lars Forsgren ${ }^{4}$, Peter Hagell ${ }^{1}$
}

\begin{abstract}
Background: The Freezing of Gait Questionnaire (FOGQ) was developed in response to the difficulties of observing and quantifying freezing of gait (FOG) clinically as well as in laboratory settings. However, as the FOGQ is a clinician-administered patient-reported rating scale it cannot be used in postal surveys. Here we report the development and measurement properties of a self-administered version of the FOGQ (FOGQsa).

Methods: A clinical sample and a postal survey sample of non-demented people with Parkinson's disease (PD; total $n=225$ ) completed the FOGQsa and questionnaires concerning physical functioning (PF) and fall-related self efficacy (FES). Additional questions (No/Yes) regarded previous falls and whether they were afraid of falling. The clinical sample was also assessed with the Unified PD Rating Scale (UPDRS). Thirty-five participants completed FOGQsa and were also assessed with the original version (FOGQ) in a clinical interview.
\end{abstract}

Results: There were no differences ( $P=0.12$ ) between FOGQ (median, 10; $q 1-q 3,2-14)$ and FOGQsa (median, 8; 214) scores. The Spearman $\left(r_{s}\right)$ and intra-class correlations between the two were 0.92 and $0.91(95 \% \mathrm{Cl}, 0.82-0.95)$, respectively. For FOGQsa, corrected item-total correlations ranged between 0.68-0.89. Reliability was $0.93(95 \% \mathrm{Cl}$, 0.91-0.94). FOGQsa scores correlated strongest with UPDRS Item 14 (Freezing; $\left.r_{s}, 0.76\right)$ and with FES $\left(r_{s},-0.74\right)$. The weakest correlation was found with age $\left(r_{s}, 0.14\right)$. Fallers scored significantly $(p<0.001)$ higher on FOGQsa compared to non-fallers, median scores $8(q 1-q 3,4-14)$ versus $2(0-7)$. Those expressing a fear of falling scored higher $(p<0.001)$ than those who did not, median scores $2(0-7)$ versus $6(2-14)$.

Conclusions: The present findings indicate that the FOGQsa is as reliable and valid as the original interview administered FOGQ version. This has important clinical implications when investigating FOG in large scale studies.

\section{Background}

Up to $50 \%$ of people with Parkinson's disease (PD) experience sudden and transient motor blocks (freezing) while initiating or performing activities [1]. Freezing of gait (FOG) is often described as if the feet are glued to the ground $[1,2]$. This description is recommended to use when asking people with PD about the phenomenon [3]. FOG typically appears when initiating the first step (start hesitation), on turning or when approaching a target (destination hesitation or "target freezing") [1,2]. FOG is usually evoked in crowded and confined spaces as well as in time limiting situations, e.g., when crossing a street $[1,2,4-7]$.

The presence and severity of FOG has been found to be associated with longer disease duration $[1,7,8]$, more

\footnotetext{
* Correspondence: Maria_H.Nilsson@med.lu.se

'Department of Health Sciences, Lund University, Lund, Sweden

Full list of author information is available at the end of the article
}

advanced disease stage $[1,7,8]$, falls [6,9-13], dyskinesias [1] and decreased mobility [14]. FOG is in fact one of the most distressing symptoms in PD [15], and it has a negative impact on patient perceived health $[14,16]$.

FOG is characterized by its unpredictable and episodic nature. It typically occurs as short lasting episodes at home, which makes it difficult to observe and quantify during clinical testing as well as in laboratory settings $[17,18]$. Evaluating FOG is commonly done by either posing a question or by using a single item assessment such as item 14 of the Unified PD Rating Scale (UPDRS) [8-10,13]. Therefore, Giladi et al. developed the Freezing of Gait Questionnaire (FOGQ) which is a clinician/interview administered patient-reported rating scale [19]. The FOGQ consists of six items scored from $0-4$. The total score ranges from 0 to 24 , and higher scores denote more severe FOG. 
The FOGQ was originally tested for reliability (Cronbach's alpha, 0.94) and validity in 40 people with PD [19]. However, although the FOGQ appears to be a useful and valid tool for its purpose, the dependency on a clinician to interview the patient and to demonstrate the meaning of FOG is also limiting. For example, the tool becomes somewhat time consuming for implementation in clinical practice and cannot be used for larger scale postal surveys. A completely self-administered FOGQ scale that provides the same type of information would therefore be of great benefit.

This study assessed the validity and reliability of a selfadministered version of the FOGQ, i.e. the FOGQsa. In addition, we explored the relationships between FOGQsa scores and patient demographics, fear of falling, falls, gait, motor complications and physical functioning.

\section{Methods}

The study was divided into two phases: (1) development of a self-administered version of FOGQ (the FOGQsa) and (2) testing the psychometric properties of the FOGQsa.

\section{Development of the FOGQsa}

The intention was to preserve the semantic content of all six original FOGQ items but with revisions of the wording to make them applicable for self-administration. In accordance with the original FOGQ instrument [19], responses should be based on experiences over the last week except for item 3. As in the original FOGQ scale, all items are scored from 0-4 (possible total score range, 0-24; higher scores $=$ more severe FOG).

To substitute for the demonstration and description of FOG in the FOGQ, a cover sheet explaining the FOG phenomenon was developed for the FOGQsa. The description was based on a review of the literature, and it was constructed in close interaction with two nurses and two neurologists specialized in PD. The cover sheet describes that FOG is typically experienced as if "the feet are glued to the ground", and that this can happen while trying to initiate walking, while walking (which could be accompanied by taking smaller and smaller steps) or while turning. Other provocative factors are also described such as walking in confined spaces (e.g. passing a doorway), target hesitation (e.g. just before approaching a chair when sitting down) and when having limited time (e.g. crossing a street) [1,2,4-7].

Following modification of the FOGQ into the FOGQsa, face-to-face field-test interviews were conducted with 14 non-demented people with PD (9 men) with varying degrees of motor complications and/or gait disturbances to assess clarity of wording, face validity and respondent burden.

\section{Psychometric properties of the FOGQsa Participants}

Data collection included a clinical sample and a postal survey sample of non-demented people with idiopathic PD [20].

The clinical sample consisted of a convenience sample with varying degrees of motor complications and/or gait disturbances receiving out-patient care at a Swedish university hospital (Table 1). Fifty patients were invited to participate. Eight patients declined participation and five patients were unable to attend the study appointment. An additional participant did not complete the FOGQsa and was therefore excluded. Thus, 36 participants were included.

The postal survey sample was recruited from another Swedish university hospital (Table 1). The survey was sent to 282 patients ( $39 \%$ female), and 231 were returned, of which 191 were completed (43\% female; conservative total response rate, 68\%). Thirty-eight questionnaires were returned completely blank and two were returned to sender due to change of address. Out of the 191 responders, two had left all items of the FOGQsa blank. These two participants were excluded, leaving 189 participants for analyses. Demographic data of all 225 participants are presented in Table 1.

\section{Instruments}

All participants completed the FOGQsa, the Swedish version of the Falls-Efficacy Scale, FES(S) [21], and the Physical Functioning (PF) scale of the Medical Outcomes Study 36-Item Short-Form Health Survey (SF-36) [22].

FES(S) assesses fall-related self-efficacy, and the 13 activities are rated from 0 (not confident at all) to 10 (completely confident) [21]. The total score can range from 0 to 130 . PF comprises ten items about physical activities [22]. The score can range from 0 to 100 , where higher scores denote better physical functioning. Additional questions included whether participants had fallen during the past six months (No/Yes) and if they were afraid of falling (No/Yes). The clinical sample was also asked whether they felt unsteady while turning (No/Yes).

\section{Procedure}

The FOGQsa was mailed to the clinical sample before the study visit. The participants were instructed to complete it three days before the visit, put the completed questionnaire in an envelope, seal it and bring it to the study visit. Demographic data (Table 1) were collected through self report for all participants, which the clinical sample completed at their out-patient visit. Demographic questions preceded the included self-administered questionnaires. In addition, the clinical sample was assessed with timed gait tests: ten meter walk test (gait speed, both comfortable and fast) and Timed Up \& Go (TUG). 
Table 1 Participants' characteristics

\begin{tabular}{|c|c|c|c|}
\hline & $\begin{array}{l}\text { Total sample } \\
\mathrm{n}=\mathbf{2 2 5}\end{array}$ & $\begin{array}{l}\text { Clinical sample } \\
\mathrm{n}=36\end{array}$ & $\begin{array}{l}\text { Postal survey } \\
\mathrm{n}=189\end{array}$ \\
\hline \multirow[t]{3}{*}{ Mean age, years (SD, min.-max.) } & $69.1(8.9)$ & $65.3(6.2)$ & $69.9(9.1)$ \\
\hline & $42.0-91.0$ & $49.0-83.0$ & $42.0-91.0$ \\
\hline & $n=221$ & $n=36$ & $\mathrm{n}=185$ \\
\hline \multirow[t]{3}{*}{ Mean PD-duration, years (SD, min.-max.) } & $7.7(6.8)$ & $14.6(8.3)$ & $6.2(5.5)$ \\
\hline & $0.33-44.0$ & $2.2-44.0$ & $0.33-28.0$ \\
\hline & $n=210$ & $n=36$ & $n=174$ \\
\hline \multirow[t]{3}{*}{ Gender (men/women), n (\%) } & $137(62 \%) /$ & $29(81 \%) /$ & $108(58 \%) /$ \\
\hline & $84(38 \%)$ & $7(19 \%)$ & $77(42 \%)$ \\
\hline & $n=221$ & $n=36$ & $\mathrm{n}=185$ \\
\hline \multirow[t]{3}{*}{ Falls past 6 months (yes/no), n (\%) } & $88(40 \%) /$ & $19(53 \%) /$ & $69(38 \%) /$ \\
\hline & $131(60 \%)$ & $17(47 \%)$ & $114(62 \%)$ \\
\hline & $n=219$ & $n=36$ & $n=183$ \\
\hline \multirow[t]{4}{*}{ Fear of falling (yes/no), n (\%) } & $94(43 \%) /$ & $9(25 \%) /$ & $85(46 \%) /$ \\
\hline & $125(57 \%)$ & $27(75 \%)$ & $98(54 \%)$ \\
\hline & $n=219$ & $n=36$ & $n=183$ \\
\hline & Median, $q 1-q 3$ & Median, q1-q3 & Median, q1-q3 \\
\hline \multirow[t]{3}{*}{ Falls-Efficacy Scale (S) } & 112.0 & 106.5 & 114.0 \\
\hline & $75.0-130.0$ & $94.8-129.0$ & $69.0-130.0$ \\
\hline & $n=183$ & $\mathrm{n}=30$ & $n=153$ \\
\hline \multirow[t]{3}{*}{ Physical Functioning (PF, SF-36) } & 55.0 & 24.0 & 60.0 \\
\hline & $29.0-75.0$ & $20.0-28.0$ & $35.0-80.0$ \\
\hline & $n=218$ & $\mathrm{n}=30$ & $n=188$ \\
\hline \multirow[t]{3}{*}{ Item 13, UPDRS II (Falling) } & 0.0 & 0.0 & 0.0 \\
\hline & $0.0-1.0$ & $0.0-1.0$ & $0.0-1.0$ \\
\hline & $n=223$ & $n=36$ & $n=187$ \\
\hline \multirow[t]{3}{*}{ Item 14, UPDRS II (Freezing) } & 0.0 & 0.0 & 0.0 \\
\hline & $0.0-1.0$ & $0.0-1.8$ & $0.0-1.0$ \\
\hline & $n=221$ & $n=36$ & $n=185$ \\
\hline \multirow[t]{3}{*}{ Item 15, UPDRS II (Walking) } & 1.0 & 1.0 & 1.0 \\
\hline & $0.0-2.0$ & $0.0-1.0$ & $0.0-2.0$ \\
\hline & $n=221$ & $n=34$ & $\mathrm{n}=187$ \\
\hline
\end{tabular}

Falls-Efficacy Scale, Swedish version; the total score can range between 0-130 (higher scores = better). Physical Functioning (PF, SF-36); total score range between 0-100 (higher scores = better).

Item 13, 14 and 15 of the UPDRS part II; each item graded from 0-4 (higher scores = greater severity).

Additional data regarding the participants are presented in Table 3.

Each gait test had one practice trial and one test trial. The FOGQ was thereafter administered as a clinical interview including a demonstration of FOG [19]. That is, the assessor demonstrated typical manifestations of start hesitation, freezing at the doorway and while turning. Finally, clinical assessments according to the UPDRS and Hoehn \& Yahr stages (HY) [23] were conducted by an independent assessor who was unaware of previous test results. HY was also assessed for the "off" phase based on patient-reported history. In the postal survey sample, self administered versions of UPDRS items 13 (falling), 14 (freezing) and 15 (walking) were included [24]. All participants of the postal survey sample received a reminder about ten days after the first administration.
The study was reviewed by the local ethics advisory committee, and the included participants gave their written informed consent.

Analyses The primary aim of the analyses was to explore to what extent the FOGQsa scores reproduced the findings of the original FOGQ instrument $[7,19,25]$.

We thus explored whether the assumptions for summing FOGQsa item scores into a total score were met [26]. That is, we examined whether item mean scores and standard deviations were roughly similar and if the corrected item-total correlations exceeded 0.3. Whether the items appear to represent a common variable was considered supported if corrected item-total correlations were $\geq 0.4[26]$. 
Floor and ceiling effects (i.e., the proportion of people obtaining minimum and maximum scores, respectively) were examined, and should be $<15-20 \%$ [27,28]. Reliability (Cronbach's alpha) was also estimated, and should be $\geq 0.8$ [29]. In addition, the standard error of measurement (SEM) was estimated using the formula:

$$
\mathrm{SEM}=\mathrm{SD} \times \sqrt{ }(1-\alpha)
$$

Using data from the clinical sample, we assessed the relationship between the original FOGQ and the FOGQsa through Spearman $\left(\mathrm{r}_{\mathrm{S}}\right)$ and intra-class correlations (ICC; one-way random model). The correlations were expected to be strong $(>0.8)$ in order to support criterion-related validity. Construct validity was assessed by examining the pattern of correlations $\left(r_{S}\right)$ between FOGQsa and UPDRS scores. To replicate the patterns reported for the original version of FOGQ [19,25], the correlation with FOGQsa scores was expected to be strongest for UPDRS part II (Activities of Daily Living, ADL) and weakest for UPDRS part I (mentation, behavior and mood) $[7,19,25]$. Among individual UPDRS items, we expected a stronger correlation between FOGQsa scores and item 14 (freezing) than with items 13 (falling unrelated to freezing), 15 (walking), 29 (gait) and 30 (postural stability) $[19,25]$. The correlation with disease severity (HY) was expected to be stronger in the "off" state than in the "on" state [25].

In addition, we examined the relationships between FOGQsa scores and patient demographics, FES(S), timed gait tests, dyskinesias (items 32-35 of the UPDRS part IV), motor fluctuations (items 36-39 of the UPDRS part IV) and PF. We expected the FOGQsa scores to correlate stronger with dyskinesia, motor fluctuations and FES(S) scores than with gait tests [25]. The weakest correlation was expected with age [25]. We also assessed differences (Mann-Whitney U test) in FOGQsa scores between people who did and did not report falls, fear of falling and unsteadiness while turning. It was expected that fallers, those reporting fear of falling and those being unsteady while turning would score higher.

Analyses were performed using SPSS 15 (SPSS Inc., Chicago, IL) and ScoreRelCI (Barnette 2005). Two-tailed p-values $<0.05$ were considered statistically significant. $\mathrm{P}$-values were not corrected for multiple testing.

\section{Results}

Field-test participants had a mean age of 64 (SD, 5.2) years and an average PD-duration of 16 (SD, 5.5) years. All 14 participants found the description of FOG to be clear and understandable and items were considered relevant and easy to answer. One participant commented that the duration of freezing was somewhat difficult to estimate. Two comments related to the frequency of freezing. However, no changes in the questionnaire were deemed necessary due to these comments. The mean time for completing FOGQsa was 3 (SD, 1.3) minutes.

For the total sample, mean and SD for FOGQsa items scores ranged between 0.76-1.6 and 1.1-1.4, respectively (Table 2). Corrected item-total correlations ranged between 0.68-0.89. Forty-one participants (19\%) scored 0 , and none reached the maximum score of 24 . Reliability was 0.93 (95\% CI, 0.91-0.94), and SEM was 1.6. Results for the two subsamples were similar (Table 2). Total FOGQsa scores could be computed for 214 (95\%) out of the 225 participants.

Data for both the FOGQsa and the original FOGQ were available for 35 people in the clinical sample. There were no differences $(P=0.12)$ between FOGQ (median, 10; q1-q3, 2-14) and FOGQsa (median, 8; q1$\mathrm{q} 3,2-14)$ scores. The Spearman and intra-class correlations were 0.92 and 0.91 (95\% CI, 0.82-0.95), respectively (Figure 1). The mean number of days between completions was 2.6 (SD, 0.80).

The relationships between FOGQsa scores and other variables are presented in Table 3. The FOGQsa scores for the total sample showed the strongest correlation with UPDRS item 14 (Freezing; $r_{s}, 0.76$ ) and with FES(S) $\left(r_{s},-0.74\right)$. The weakest correlation was found with age $\left(r_{s}, 0.14\right)$. For common variables, both samples showed similar patterns (Table 3). However, the clinical sample showed a stronger correlation with UPDRS part II $\left(r_{\mathrm{s}}\right.$, 0.68) than with FES(S) $\left(r_{s},-0.57\right)$ (Table 3).

FOGQsa scores did not differ ( $p>0.3$ ) between genders. For the total sample, the median score was 4 for both women and men (q1-q3, 1-9 and 1-11, respectively). Out of the 225 participants, 219 responded to the question whether they had fallen during the past six months. Fallers $(88 / 219 ; 40 \%)$ scored significantly $(\mathrm{p}<0.001)$ higher on FOGQsa compared to non-fallers, median scores 8 ( $\mathrm{q} 1-\mathrm{q} 3,4-14)$ versus 2 (q1-q3,0-7). Those expressing a fear of falling scored higher $(\mathrm{p}<0.001)$ than those who did not, median scores 2 (q1-q3, 0-7) versus 6 (q1-q3, 2-14). In the clinical sample, those reporting unsteadiness while turning $(20 / 35 ; 57 \%)$ had significantly ( $\mathrm{p}=0.030$ ) higher FOGQsa scores than those who did not, median scores 11 (q1-q3, 6-16) versus 2 (0-13).

\section{Discussion}

The present findings indicate that the FOGQsa is as reliable and valid as the original interview administered FOGQ version. Specifically, our observations support the legitimacy of summing item scores into a reliable total score that corresponds closely to FOGQ scores. In addition, construct validity is supported by a correlation pattern very similar to that reported for the original FOGQ version. This has important clinical implications when investigating FOG. 
Table 2 Descriptive and psychometric FOGQsa data

\begin{tabular}{|c|c|c|c|c|c|c|c|}
\hline \multirow[b]{2}{*}{ Item } & & \multicolumn{2}{|c|}{$\begin{array}{l}\text { Total sample } \\
\mathrm{n}=225\end{array}$} & \multicolumn{2}{|c|}{$\begin{array}{l}\text { Clinical sample } \\
\mathrm{n}=36\end{array}$} & \multicolumn{2}{|c|}{$\begin{array}{l}\text { Postal survey sample } \\
\mathrm{n}=189\end{array}$} \\
\hline & & Mean (SD) & $\begin{array}{l}\text { Corrected Item-total } \\
\text { correlations } n=214\end{array}$ & Mean (SD) & $\begin{array}{l}\text { Corrected Item-total } \\
\text { correlations } \mathrm{n}=35\end{array}$ & Mean (SD) & $\begin{array}{l}\text { Corrected Item-total } \\
\text { correlations } \mathrm{n}=179\end{array}$ \\
\hline 1 & "Walking during worst state" & $\begin{array}{l}1.6(1.1) \\
2 \text { missing }\end{array}$ & 0.68 & $\begin{array}{l}1.7(1.2) \\
1 \text { missing }\end{array}$ & 0.87 & $\begin{array}{l}1.6(1.1) \\
1 \text { missing }\end{array}$ & 0.64 \\
\hline 2 & $\begin{array}{l}\text { "Gait difficulties affecting } \\
\text { daily activities and } \\
\text { independence" }\end{array}$ & $\begin{array}{l}1.1(1.1) \\
2 \text { missing }\end{array}$ & 0.68 & $\begin{array}{l}1.2(1.1) \\
1 \text { missing }\end{array}$ & 0.76 & $\begin{array}{l}1.1(1.2) \\
1 \text { missing }\end{array}$ & 0.68 \\
\hline 3 & $\begin{array}{l}\text { "Feet getting glued to the } \\
\text { floor" }\end{array}$ & $\begin{array}{l}1.1(1.4)^{1} \\
3 \text { missing }\end{array}$ & 0.83 & $1.7(1.4)$ & 0.82 & $\begin{array}{l}1.0(1.4) \\
2 \text { missing }\end{array}$ & 0.84 \\
\hline 4 & $\begin{array}{l}\text { "Duration of longest freezing } \\
\text { episode" }\end{array}$ & $\begin{array}{l}0.87 \text { (1.3) } \\
7 \text { missing }\end{array}$ & 0.89 & $1.6(1.6)$ & 0.91 & $\begin{array}{l}0.73(1.1) \\
7 \text { missing }\end{array}$ & 0.90 \\
\hline 5 & $\begin{array}{l}\text { "Duration of typical start } \\
\text { hesitation" }\end{array}$ & $\begin{array}{l}0.76(1.1) \\
6 \text { missing }\end{array}$ & 0.88 & $1.2(1.4)$ & 0.85 & $\begin{array}{l}0.67(1.1) \\
6 \text { missing }\end{array}$ & 0.89 \\
\hline \multirow[t]{7}{*}{6} & $\begin{array}{l}\text { "Duration of typical turning } \\
\text { hesitation" }\end{array}$ & $\begin{array}{l}0.76(1.1) \\
5 \text { missing } \\
\end{array}$ & 0.83 & $1.1(1.4)$ & 0.78 & $\begin{array}{l}0.68(1.1) \\
5 \text { missing } \\
\end{array}$ & 0.85 \\
\hline & & \multicolumn{2}{|l|}{$\begin{array}{l}\text { Total score } \\
\mathrm{n}=214\end{array}$} & \multicolumn{2}{|l|}{$\begin{array}{l}\text { Total score } \\
\mathrm{n}=35\end{array}$} & \multicolumn{2}{|l|}{$\begin{array}{l}\text { Total score } \\
\mathrm{n}=179\end{array}$} \\
\hline & Mean (SD) & \multicolumn{2}{|l|}{$6.1(6.2)$} & \multicolumn{2}{|l|}{$8.6(7.2)$} & \multicolumn{2}{|l|}{$5.6(5.9)$} \\
\hline & Median, q1-q3 & \multicolumn{2}{|l|}{$4.0,1.0-4.0$} & \multicolumn{2}{|l|}{$\begin{array}{l}8.0,2.0- \\
14.0\end{array}$} & \multicolumn{2}{|l|}{$4.0,1.0-9.0$} \\
\hline & Min-max & \multicolumn{2}{|l|}{$0-22$} & \multicolumn{2}{|l|}{$0-22$} & \multicolumn{2}{|l|}{$0-22$} \\
\hline & $\begin{array}{l}\text { \% scoring minimum } \\
(0) / \text { maximum (24) }\end{array}$ & \multicolumn{2}{|l|}{$19 / 0$} & \multicolumn{2}{|l|}{$17 / 0$} & \multicolumn{2}{|l|}{$20 / 0$} \\
\hline & $\begin{array}{l}\text { Reliability, Cronbach's alpha } \\
(95 \% \text { Cl) }\end{array}$ & \multicolumn{2}{|c|}{$0.93(0.91-0.94)$} & \multicolumn{2}{|c|}{$0.94(0.90-0.97)$} & \multicolumn{2}{|c|}{$0.93(0.91-0.94)$} \\
\hline
\end{tabular}

FOGQsa: Freezing of Gait Questionnaire, self administered version. Each item is scored between 0-4, and the total score thus ranges between 0-24. Higher scores denote more severe FOG.

Some participants left certain items blank. Total scores could therefore be computed for 214 out of the 225 (95\%).

${ }^{1}$ On item 3, 126 scored 0, i.e. they never experienced freezing episodes, whereas 96 out of the 214 (45\%) scored at least 1 and could be defined as "freezers".

Out of the 96 reporting freezing episodes, 51 did so "often- about once a day" and 11 "always- whenever walking".

Snijders et al. highlighted that the original FOGQ does not include provocative circumstances of FOG [3].

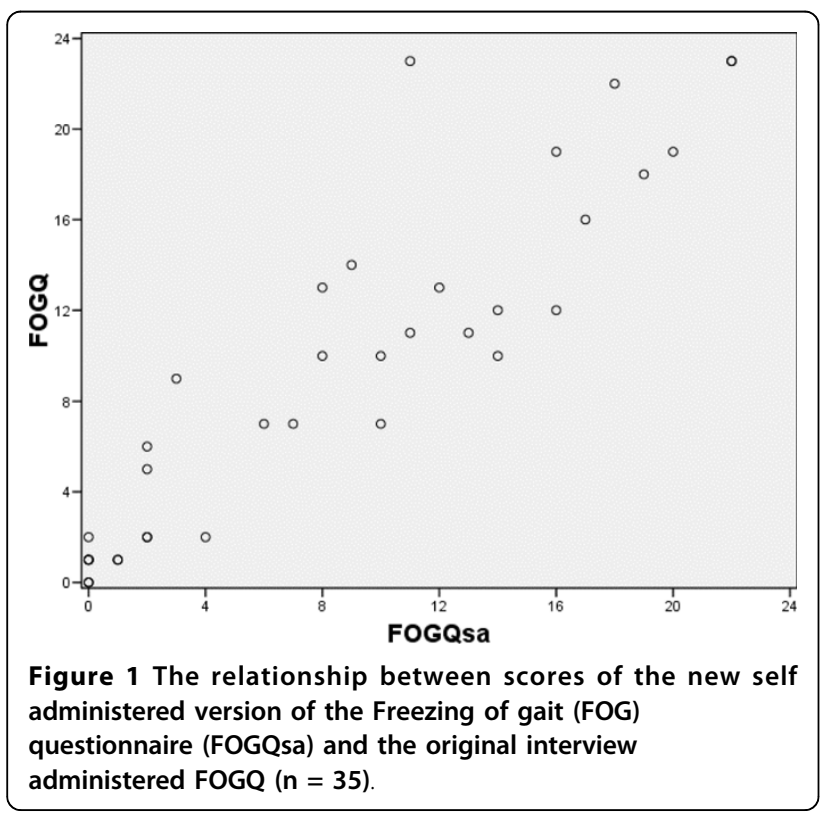

When using a self-administered assessment it is crucial that the investigated construct is well defined and described. The cover sheet of the FOGQsa was created in order to make certain that the individual recognizes and fully understands the investigated phenomenon. It therefore included both environmental and circumstantial factors that may provoke FOG; narrow space (e.g. passing a doorway) $[1,2,6,7]$, crowded space and limited time, e.g. trying to cross a busy street $[2,4-6]$. The original FOGQ does not mention target hesitation although FOG is known to occur when reaching a target $[1,2,4,5]$. This new self administered version does, however, include target hesitation when describing FOG. Field testing of the FOGQsa revealed that the participants considered the content to be both clear and relevant. The respondent burden was marginal as indicated by a short completion time.

FOGQsa had an internal consistency reliability above 0.90 and thus exceeded the recommendation of 0.80 [29]. This finding is similar to the results for the original FOGQ version $[7,19,25]$. In a separate pilot study, we have also found its test-retest reliability to be adequate (ICC, 0.85) [30]. However, further studies investigating 
Table 3 Correlations with FOGQsa and descriptive values for clinical tests

\begin{tabular}{|c|c|c|c|c|c|c|}
\hline & \multicolumn{2}{|c|}{$\begin{array}{l}\text { Total sample } \\
\mathrm{n}=225\end{array}$} & \multicolumn{2}{|c|}{$\begin{array}{l}\text { Clinical sample } \\
\mathrm{n}=36\end{array}$} & \multicolumn{2}{|c|}{$\begin{array}{l}\text { Postal survey } \\
\mathrm{n}=189\end{array}$} \\
\hline & $r_{5}$ & $p$-value & $r_{s}$ & p-value & $r_{s}$ & p-value \\
\hline Age, years & 0.14 & 0.046 & 0.07 & $>0.3$ & 0.21 & 0.006 \\
\hline PD-duration, years & 0.42 & $<0.001$ & 0.50 & 0.002 & 0.40 & $<0.001$ \\
\hline Falls-Efficacy Scale & -0.74 & $<0.001$ & -0.57 & 0.001 & -0.78 & $<0.001$ \\
\hline Physical Functioning (PF, SF-36) & -0.61 & $<0.001$ & -0.50 & 0.006 & -0.68 & $<0.001$ \\
\hline Item 13, UPDRS II (Falling) & 0.49 & $<0.001$ & 0.53 & 0.001 & 0.49 & $<0.001$ \\
\hline Item 14, UPDRS II (Freezing) & 0.76 & $<0.001$ & 0.72 & $<0.001$ & 0.78 & $<0.001$ \\
\hline Item 15, UPDRS II (Walking) & 0.57 & $<0.001$ & 0.56 & 0.001 & 0.64 & $<0.001$ \\
\hline Clinical sample, $\mathrm{n}=36$ & \multicolumn{2}{|c|}{ Median (q1-q3) } & $r_{s}$ & p-value & & \\
\hline UPDRS I, Mentation, behavior and mood & \multicolumn{2}{|c|}{$2.0(0-3.0)$} & 0.33 & 0.059 & & \\
\hline UPDRS II, Activities of Daily Living & \multicolumn{2}{|c|}{$7(3.0-13.5)$} & 0.68 & $<0.001$ & & \\
\hline UPDRS III, Motor examination & \multicolumn{2}{|c|}{$15.0(8.0-20.0)$} & 0.55 & 0.001 & & \\
\hline Item 29, UPDRS III (Gait) & \multicolumn{2}{|c|}{$0.5(0-1.0)$} & 0.46 & 0.006 & & \\
\hline Item 30, UPDRS III (Postural stability) & \multicolumn{2}{|c|}{$1.0(0-2.0)$} & 0.49 & 0.003 & & \\
\hline Hoehn and Yahr ("on") & \multicolumn{2}{|c|}{$3.0(2.0-3.0)$} & 0.44 & 0.009 & & \\
\hline Hoehn and Yahr ("off") & \multicolumn{2}{|c|}{$3.0(3.0-4.0)$} & 0.58 & $<0.001$ & & \\
\hline Dyskinesias (UPDRS IV, items 32-35) & \multicolumn{2}{|c|}{$2.5(1.0-5.0)$} & 0.63 & $<0.001$ & & \\
\hline Motor fluctuations (UPDRS IV, items 36-39) & \multicolumn{2}{|c|}{$3.0(1.3-3.8)$} & 0.60 & $<0.001$ & & \\
\hline Timed Up \& Go, sec (Mean, SD) & \multicolumn{2}{|c|}{$9.7(2.7)$} & 0.34 & 0.049 & & \\
\hline Comfortable gait speed, m/s (Mean, SD) & \multicolumn{2}{|c|}{$1.32(0.23)$} & -0.29 & 0.094 & & \\
\hline Fast gait speed, m/s (Mean, SD) & \multicolumn{2}{|c|}{$1.60(0.40)$} & -0.33 & 0.055 & & \\
\hline
\end{tabular}

Falls-Efficacy Scale, Swedish version; the total score can range between 0-130 (higher scores = better).

Physical Functioning (PF, SF-36); total score can range between 0-100 (higher scores = better).

Item 13, 14 and 15 of the UPDRS part II; each item graded from 0-4 (higher scores = greater severity).

UPDRS part I; total score range 0-16 (16 = greater severity). UPDRS part II; total score range 0-52 (52 = greater severity). UPDRS part III; total score range 0-108

$(108$ = greater severity).

Dyskinesias (UPDRS part IV, items 32-35); total score range 0-13 (13 = greater severity).

Motor fluctuations (UPDRS part IV, items 36-39); total score range 0-7 (7 = greater severity).

its test-retest reliability are warranted. In the present study, $19 \%$ of the participants scored 0 (best possible score). Both FOGQ and FOGQsa consist of six items, where four items assess FOG severity and two items concern gait difficulties in general. Our results thus suggest that about $20 \%$ of the participants had neither gait difficulties nor FOG. In a study by Schrag et al., impaired gait was reported by $75 \%$ of people with a PD-duration of at least five years [31]. In another study, $21 \%$ out of 290 people with PD reported no gait problems [32]. The observed floor effect (i.e. percentage scoring 0 ) thus appears reasonable in the current targeted population. Reasonable floor and ceiling effects are a prerequisite for detection of differences [33]. Potential differences need also to exceed the measurement error in order to indicate a true change. The SEM observed in this study suggests that the change in scores need to be at least 1.7 in order to exceed the measurement error.

FOGQsa scores distinguished between fallers and nonfallers. Both fallers and those expressing a fear of falling had significantly higher FOGQsa scores than those not reporting these problems. This is not surprising since freezing is associated with falls [6,9-13]. Those who reported being unsteady while turning also had higher FOGQsa scores than those not reporting unsteadiness. In a study investigating 130 persons with $\mathrm{PD}$, turning around was the factor most commonly identified to induce freezing [6]. Turning is also associated with falls $[9,11,34]$, and falls associated with freezing are in fact more likely to result in an injury [9]. This underlines the importance of including an assessment of FOG when investigating falls in people with PD. Availability of a self-administered FOGQ may facilitate this in clinical practice.

When assessing FOG, Snijders et al. advocate combining physical examinations with more specific questions about FOG [3]. However, this is not possible when conducting postal surveys. FOGQ scores have also been shown to correlate only weakly with timed gait tests [25]. This indicates the need for using patient reported tools, especially since FOG is difficult to capture during a clinical or laboratory investigation $[17,18]$. The FOGQ is then preferable to using a single item approach, which is less reliable and less responsive to change [35]. Taken together, the present results speak in favor of 
using the FOGQsa when investigating FOG, falls and fear of falling in survey studies.

There are some methodological concerns which need to be taken into consideration. Demented patients were excluded, and the clinical sample was not randomly selected. This might affect the external validity of the present findings. The lack of maximum scores may suggest a bias towards less severe problems in the current sample. However, the highest observed score (22) is very close to the maximum score of 24 , and the observed rate of people scoring zero on the FOGQsa is consistent with observations in previous studies (see above). Furthermore, validation of the FOGQsa (as well as the FOGQ) has been based on subjective data. Future studies may therefore consider adding ambulatory monitoring of FOG [36]. Finally, the fact that FOGQ includes two items concerning gait difficulties in general has been criticized, and these items were therefore omitted in a recent revised version of the FOGQ [37]. The revised version supplies a video-demonstration of FOG, but it is not self-administered. We have now initiated an adaptation in order to create a self-administered version of the revised version as well.

The Swedish FOGQsa described here can be obtained from the corresponding author. An English language version is under development and will also be obtainable from the corresponding author when available.

\section{Conclusions}

In conclusion, we report the development and testing of the FOGQsa, a self administered version of the FOGQ. Its measurement properties are very similar to those previously reported for the FOGQ, suggesting that it is as reliable and valid as the original interview administered version. Importantly, FOGQsa scores do not differ from and correlate strongly with FOGQ scores. These findings suggest that no substantial information is lost by using the self administered version as compared to the clinician administered FOGQ. This facilitates the investigation of FOG in postal surveys and clinical practice. Further studies are warranted in order to scrutinize the measurement properties of the FOGQsa in more detail.

\section{Acknowledgements}

The authors wish to thank the patients for their cooperation; Jan Reimer, Stina Bladh, Martina Eliasson, Mona Edström and Birgitta Wikström for assistance with data collection.

\section{Funding:}

The study was supported by the Swedish Research Council, the Swedish Parkinson Foundation, the Swedish Parkinson Academy, Skane County Council's Research and Development Foundation, and the Faculty of Medicine at Lund University, Lund, Sweden.

This study was accomplished within the context of the Centre for Ageing and Supportive Environments (CASE), Lund University, Sweden, funded by the Swedish Council for Working Life and Social Research.

\section{Author details}

${ }^{1}$ Department of Health Sciences, Lund University, Lund, Sweden.

${ }^{2}$ Department of Clinical Sciences, Division of Neurosurgery, Skåne University Hospital, Lund, Sweden. ${ }^{3}$ Department of Community Medicine and Rehabilitation, Umeå University, Umeå, Sweden. ${ }^{4}$ Department of Pharmacology and Clinical Neuroscience, Umeå University, Umeå, Sweden. ${ }^{5}$ Department of Clinical Sciences, Division of Neurology, Skåne University Hospital, Lund, Sweden.

\section{Authors' contributions}

MN conceived the study (including the development of the FOGQsa), participated in its design, data collection, conducted the statistical analyses, interpreted data and drafted the first manuscript.

G-M.H participated in designing the study, coordinated the survey study, participated in data collection and drafting the manuscript.

KW participated in designing the study, assisted in developing the FOGQsa and drafting the manuscript.

MM assisted in developing the FOGQsa and contributed to drafting the manuscript

LF participated in designing the study and drafting the manuscript. $\mathrm{PH}$ conceived the study (including the development of the FOGQsa), participated in its design, data collection, interpretation of data and drafting the manuscript.

All authors read and approved the final manuscript.

\section{Competing interests}

The authors declare that they have no competing interests.

Received: 8 June 2010 Accepted: 23 September 2010

Published: 23 September 2010

\section{References}

1. Giladi N, McMahon D, Przedborski S, Flaster E, Guillory S, Kostic V, Fahn S: Motor blocks in Parkinson's disease. Neurology 1992, 42(2):333-339.

2. Fahn S: The freezing phenomenon in parkinsonism. Advances in neurology 1995, 67:53-63.

3. Snijders AH, Nijkrake MJ, Bakker M, Munneke M, Wind C, Bloem BR: Clinimetrics of freezing of gait. Mov Disord 2008, 23(Suppl 2):S468-474.

4. Bloem BR, Hausdorff JM, Visser JE, Giladi N: Falls and freezing of gait in Parkinson's disease: a review of two interconnected, episodic phenomena. Mov Disord 2004, 19(8):871-884.

5. Okuma Y: Freezing of gait in Parkinson's disease. J Neurol 2006, 253(Suppl 7):VII27-32.

6. Rahman S, Griffin HJ, Quinn NP, Jahanshahi M: The factors that induce or overcome freezing of gait in Parkinson's disease. Behavioural neurology 2008, 19(3):127-136.

7. Giladi N, Tal J, Azulay T, Rascol O, Brooks DJ, Melamed E, Oertel W, Poewe WH, Stocchi F, Tolosa E: Validation of the freezing of gait questionnaire in patients with Parkinson's disease. Mov Disord 2009, 24(5):655-661.

8. Macht M, Kaussner Y, Moller JC, Stiasny-Kolster K, Eggert KM, Kruger HP, Ellgring H: Predictors of freezing in Parkinson's disease: a survey of 6,620 patients. Mov Disord 2007, 22(7):953-956.

9. Gray P, Hildebrand K: Fall risk factors in Parkinson's disease. J Neurosci Nurs 2000, 32(4):222-228.

10. Schaafsma JD, Giladi N, Balash Y, Bartels AL, Gurevich T, Hausdorff JM: Gait dynamics in Parkinson's disease: relationship to Parkinsonian features, falls and response to levodopa. Journal of the neurological sciences 2003, 212(1-2):47-53.

11. Michalowska M, Fiszer U, Krygowska-Wajs A, Owczarek K: Falls in Parkinson's disease. Causes and impact on patients' quality of life. Functional neurology 2005, 20(4):163-168.

12. Ashburn A, Stack E, Ballinger C, Fazakarley L, Fitton C: The circumstances of falls among people with Parkinson's disease and the use of Falls Diaries to facilitate reporting. Disability and rehabilitation 2008, 30(16):1205-1212.

13. Latt MD, Lord SR, Morris JG, Fung VS: Clinical and physiological assessments for elucidating falls risk in Parkinson's disease. Mov Disord 2009, 24(9):1280-1289. 
14. Moore O, Peretz C, Giladi N: Freezing of gait affects quality of life of peoples with Parkinson's disease beyond its relationships with mobility and gait. Mov Disord 2007, 22(15):2192-2195.

15. Backer JH: The symptom experience of patients with Parkinson's disease. J Neurosci Nurs 2006, 38(1):51-57.

16. Rahman S, Griffin HJ, Quinn NP, Jahanshahi M: Quality of life in Parkinson's disease: the relative importance of the symptoms. Mov Disord 2008, 23(10):1428-1434.

17. Nieuwboer A, De Weerdt W, Dom R, Lesaffre E: A frequency and correlation analysis of motor deficits in Parkinson patients. Disability and rehabilitation 1998, 20(4):142-150.

18. Nieuwboer A, Dom R, De Weerdt W, Desloovere K, Fieuws S, BroensKaucsik E: Abnormalities of the spatiotemporal characteristics of gait at the onset of freezing in Parkinson's disease. Mov Disord 2001, 16(6):1066-1075

19. Giladi N, Shabtai H, Simon ES, Biran S, Tal J, Korczyn AD: Construction of freezing of gait questionnaire for patients with Parkinsonism. Parkinsonism Relat Disord 2000, 6(3):165-170.

20. Gibb WR, Lees AJ: The relevance of the Lewy body to the pathogenesis of idiopathic Parkinson's disease. J Neurol Neurosurg Psychiatry 1988, 51(6):745-752

21. Hellstrom K, Lindmark B: Fear of falling in patients with stroke: a reliability study. Clinical rehabilitation 1999, 13(6):509-517.

22. Ware JE Jr, Sherbourne CD: The MOS 36-item short-form health survey (SF-36). I. Conceptual framework and item selection. Medical care 1992, 30(6):473-483

23. Fahn $S$, Elton $R$, et al: Unified Parkinson's Disease Rating Scale. In Recent developments in Parkinson's disease. Edited by: Fahn S, Marsden CD, Calne D, Goldstein M. Florham Park, N J: MacMillan Healthcare Information; 1987:2:153-163, 293-304

24. Louis ED, Lynch T, Marder K, Fahn S: Reliability of patient completion of the historical section of the Unified Parkinson's Disease Rating Scale. Mov Disord 1996, 11(2):185-192.

25. Nilsson MH, Hagell P: Freezing of Gait Questionnaire: validity and reliability of the Swedish version. Acta Neurol Scand 2009, 120(5):331-334.

26. Ware JE Jr, Harris WJ, Gandek B, et al: MAP-R for Windows: multitrait/multiitem analysis program-revised user's guide Boston: Health Assessment Lab 1997.

27. McHorney CA, Tarlov AR: Individual-patient monitoring in clinical practice: are available health status surveys adequate? Qual Life Res 1995, 4(4):293-307.

28. Holmes WC, Shea JA: Performance of a new, HIV/AIDS-targeted quality of life (HAT-QoL) instrument in asymptomatic seropositive individuals. Qual Life Res 1997, 6(6):561-571.

29. Nunnally JC, Bernstein IH: Psychometric theory New York: McGraw-Hill, Third 1994.

30. Nilsson MH, Wictorin K, Bladh S, Högstedt A, Eliasson M, Toreld C, Reimer J, Hagell P: Initial validation of a self administered version of the Freezing of Gait Questionnaire (FOGQsa). P21.12. 2nd World Parkinson Congress (WPC) Glasgow, Scotland: Mov Disord 2010, 25:S687.

31. Schrag A, Ben-Shlomo Y, Quinn N: How common are complications of Parkinson's disease? J Neurol 2002, 249(4):419-423.

32. Brozova H, Stochl J, Roth J, Ruzicka E: Fear of falling has greater influence than other aspects of gait disorders on quality of life in patients with Parkinson's disease. Neuro endocrinology letters 2009, 30(4):453-457.

33. Baron R, Elashaal A, Germon T, Hobart J: Measuring outcomes in cervical spine surgery: think twice before using the SF-36. Spine (Phila Pa 1976) 2006, 31(22):2575-2584

34. Lim I, van Wegen E, Jones D, Rochester L, Nieuwboer A, Willems AM, Baker K, Hetherington V, Kwakkel G: Identifying fallers with Parkinson's disease using home-based tests: who is at risk? Mov Disord 2008, 23(16):2411-2415.

35. Hobart JC, Cano SJ, Zajicek JP, Thompson AJ: Rating scales as outcome measures for clinical trials in neurology: problems, solutions, and recommendations. Lancet neurology 2007, 6(12):1094-1105.

36. Moore ST, MacDougall HG, Ondo WG: Ambulatory monitoring of freezing of gait in Parkinson's disease. J Neurosci Methods 2008, 167(2):340-348

37. Nieuwboer A, Rochester L, Herman T, Vandenberghe W, Emil GE, Thomaes T, Giladi N: Reliability of the new freezing of gait questionnaire: agreement between patients with Parkinson's disease and their carers. Gait \& posture 2009, 30(4):459-463.

\section{Pre-publication history}

The pre-publication history for this paper can be accessed here: http://www.biomedcentral.com/1471-2377/10/85/prepub

doi:10.1186/1471-2377-10-85

Cite this article as: Nilsson et al:: Development and testing of a self administered version of the Freezing of Gait Questionnaire. BMC Neurology 2010 10:85.

\section{Submit your next manuscript to BioMed Central and take full advantage of:}

- Convenient online submission

- Thorough peer review

- No space constraints or color figure charges

- Immediate publication on acceptance

- Inclusion in PubMed, CAS, Scopus and Google Scholar

- Research which is freely available for redistribution 